\title{
Type I kerogen-rich oil shale from the Democratic Republic of the Congo: mineralogical description and pyrolysis kinetics
}

\author{
Rajaa Bouamoud ${ }^{1}$. Ely Cheikh Moine ${ }^{2} \cdot$ Raphaèl Mulongo-Masamba $^{3} \cdot$ Adnane El Hamidi $^{1} \cdot$ Mohammed Halim $^{1}$. \\ Said Arsalane ${ }^{1}$
}

Received: 24 July 2019 / Published online: 9 November 2019

(c) The Author(s) 2019

\begin{abstract}
The Democratic Republic of the Congo holds important reserves of oil shale which is still under geological status. Herein, the characterization and pyrolysis kinetics of type I kerogen-rich oil shale of the western Central Kongo (CK) were investigated. X-ray diffraction, Fourier-transform infrared spectroscopy and thermal analysis (TG/DTA) showed that CK oil shale exhibits a siliceous mineral matrix with a consistent organic matter rich in aliphatic chains. The pyrolysis behavior of kerogen revealed the presence of a single mass loss between 300 and $550{ }^{\circ} \mathrm{C}$, estimated at $12.5 \%$ and attributed to the oil production stage. Non-isothermal kinetics was performed by determining the activation energy using the iterative isoconversional model-free methods and exhibits a constant value with $E=211.5 \pm 4.7 \mathrm{~kJ} \mathrm{~mol}^{-1}$. The most probable kinetic model describing the kerogen pyrolysis mechanism was obtained using the Coats-Redfern and Arrhenius plot methods. The results showed a unique kinetic triplet confirming the nature of kerogen, predominantly type I and reinforcing the previously reported geochemical characteristics of the CK oil shale. Besides, the calculation of thermodynamic parameters $\left(\Delta H^{*}, \Delta S^{*}\right.$ and $\left.\Delta G^{*}\right)$ corresponding to the pyrolysis of type I kerogen revealed that the process is non-spontaneous, in agreement with DTA experiments.
\end{abstract}

Keywords Type I kerogen $\cdot$ Pyrolysis kinetics $\cdot$ Isoconversional methods $\cdot$ Mineralogy $\cdot$ Central Kongo oil shale

\section{Introduction}

In order to satisfy the global energy demand and overcome the regression of conventional oil and natural gas reserves, oil shale constitutes a promising alternative resource from which fossil fuels can be produced (Ngo and Natowitz 2016). Oil shale is a sedimentary rock comprising a large portion of solid organic matter $(\mathrm{OM})$ called kerogen, heterogeneously distributed in a major mineral matrix composed

Edited by Xiu-Qiu Peng

Said Arsalane

pr.saidarsalane@gmail.com

1 Laboratory of Nanomaterials, Nanotechnologies and Environment, Center of Science of Materials, Faculty of Sciences, Mohammed V University in Rabat, Avenue Ibn Battouta, BP: 1014, 10000 Rabat, Morocco

2 Research Unit of Materials Chemistry, Faculty of Science and Technology, UNA, Nouakchott, Mauritania

3 Department of Geochemistry, Center for Geological and Mining Research (CGMR), Kinshasa, Democratic Republic of the Congo mainly of silicates, carbonates and clays (Yen and Chilingarian 1976). The kerogen part which is a three-dimensional macromolecular complex and insoluble in ordinary solvents can be converted by thermal treatment up to certain critical temperature into oil, gas and residual carbon (Demirbas 2016). Oil shale deposits are found all over the world, the largest being in USA, China, Brazil and Estonia (Dyni 2003), and several industrial plants were taken place to generate electrical energy by direct combustion or high-value fuels by pyrolysis (Dyni 2003; Yen and Chilingarian 1976). The Democratic Rebublic of the Congo (DRC) country also has important oil shale reserves, ranked first in the African continent but it is still under the geological exploration status (Delvaux and Fernandez-Alonso 2015).

The fundamental study of the pyrolysis of oil shale kerogen in laboratory conditions is crucial as it provides relevant information on hydrocarbon potential and predicts thermal behavior in order to design an efficient operating protocol for large-scale applications. Therefore, several pyrolysis processes were the subject of extensive investigation in the past decades (Bai et al. 2017; Maaten et al. 2018; Saif et al. 2017). The composition and yield of 
pyrolysis products depend on many factors, such as final temperature, heating rate and particle size. (Geng et al. 2017; Jiang et al. 2015; Maaten et al. 2018). Therefore, these factors should be optimized through the understanding of reaction mechanisms involved during pyrolysis and the determination of kinetic parameters describing the process as the activation energy, pre-exponential factor and reaction model (Li and Yue 2004; Wang et al. 2013). Several tools have been used to optimize the energy potential of oil shale pyrolysis, including thermogravimetric analysis (TGA), which allows to study in detail the thermal kinetics of different processes (Khraisha and Shabib 2002; Tiwari and Deo 2012a; Wang et al. 2014). For the most part, the main mass losses monitored during non-isothermal oil shale pyrolysis consist of moisture removal at low temperatures, kerogen degradation at around $200{ }^{\circ} \mathrm{C}-600{ }^{\circ} \mathrm{C}$ and clays and carbonates minerals decomposition at above $700{ }^{\circ} \mathrm{C}$ (Maaten et al. 2016; Strizhakova and Usova 2008).

In the literature, the kerogen pyrolysis has been reported as a complex reaction process depending on the nature of oil shale studied and its preservation environment (Maaten et al. 2016). Generally, the pyrolysis mechanism is described by two or more steps with different kinetic parameters (Bai et al. 2015a; Moine et al. 2016; Ren et al. 2015; Wang et al. 2015). Using model fitting methods, several reports admitted one or multiple first-order reaction kinetic models to describe the oil shale pyrolysis processes (Maaten et al. 2016; Wang et al. 2015). In this context, Maaten et al. (2016) found two steps in the kerogen pyrolysis process of American, Chinese and Estonian oil shales and adopted the first-order reaction for each one to estimate the activation energies and preexponential factors. On the other hand, using model-free isoconversional methods, many authors have found a variable activation energy tendency with the reaction advancement due to the multistep character of oil shale pyrolysis (Bai et al. 2015b; Janković 2013). They reported nth-order reaction model for oil shale pyrolysis mechanism, with $n$ equal or different from unity (Moine et al. 2016; Wang et al. 2015). According to Janković (2013), the pyrolysis of Brazilian oil shale was found to follow $n$ th-order reaction model with $n=1.23$. While, Moine et al. (2016) used the isoconversional Model Free methods followed by master plots Fitting method to examine the three steps mechanism of pyrolysis of Moroccan Rif oil shale. The authors concluded that all processes follow the $n$ th-order reaction model, with $n=1$ for the first and third processes, corresponding to the pyrolysis of bitumen and pyrite, respectively, and $n=1.6$ for the second process, which corresponds to the decomposition of kerogen. However, the pyrolysis of oil shale containing type I kerogen remains very limited as this type of material is very rare, except those of American and Turkish oil shales for which the thermal behavior generally leads to a single process with first-order reaction model and with an activation energies ranging between 155.2 and $363.2 \mathrm{~kJ} \mathrm{~mol}^{-1}$ (Karabakan and Yürüm 1998; Tiwari and Deo 2012b).

In the present work, the pyrolysis kinetics of oil shale originating from the western Central Kongo Formation of the DRC was investigated to illustrate the degradation mechanism governing the thermal process of $\mathrm{OM}$ and to complete the mineralogical and type I kerogen characterization, recently described in our previous report (Bouamoud et al. 2018). The pyrolysis kinetic study was monitored using TG instrument under non-isothermal conditions and the iterative forms of isoconversional model-free methods to estimate the activation energy with conversion degree, followed by Coats-Redfern and Arrhenius plot methods to get the exact reaction model $f(\alpha)$ and the pre-exponential factor $A$. Finally, the thermodynamic parameters $\left(\Delta H^{*}, \Delta G^{*}\right.$ and $\left.\Delta S^{*}\right)$ related to the thermal degradation of kerogen were determined using the activated complex theory. To our knowledge, the pyrolysis kinetic of western Central Kongo oil shale has never been the subject of a previous study.

\section{Materials and methods}

\subsection{Oil shale samples}

The oil shale (CK) samples used in the present study were collected from the western part of the Central Kongo as shown in Fig. 1 (Bouamoud et al. 2018), by our partners in the Center of Geological and Mining Research (CGMR) of Kinshasa (DRC). The sampling region is part of the Neoproterozoic PanAfrican-Brasiliano Orogenic Belts that contain two N-S-trending orogens (Cailteux et al. 2015). It takes the core of the Central African shield and can be determined as an assembly of Archean fragments, including the Kasai, Mbomou and the Chaillu-Gabon cratons, which were once overtaken with the Sao Francisco (Brazil) craton, to form the amalgamated Central African landmass at the time of Gondwana assembly (Daly et al. 1992; Roberts et al. 2015). Samples were taken from unexposed layers to air in order to avoid weathering impacts in an area with great similarity of rock deposits. Before the experiments, the sample was ground and sieved to the size of less than $180 \mu \mathrm{m}$ ( $80 \mathrm{mesh}$ ), according to the International Confederation for Thermal Analysis and Calorimetry (ICTAC) committee recommendations and American ASTM standard (E11) (Vyazovkin et al. 2014). The Rock-Eval parameters and mineralogical analysis of the CK samples obtained in our previous geochemical study are summarized in Table 1 (Bouamoud et al. 2018). As can be seen from the results in Table 1, the OM of CK oil shale presented a very good organic richness $(\mathrm{TOC}=10.77 \%)$ with a very good petroleum potential ( $\mathrm{S} 2=80.4 \mathrm{mgHC} / \mathrm{g}$ rock). In addition, the elemental analysis showed a high value of the 


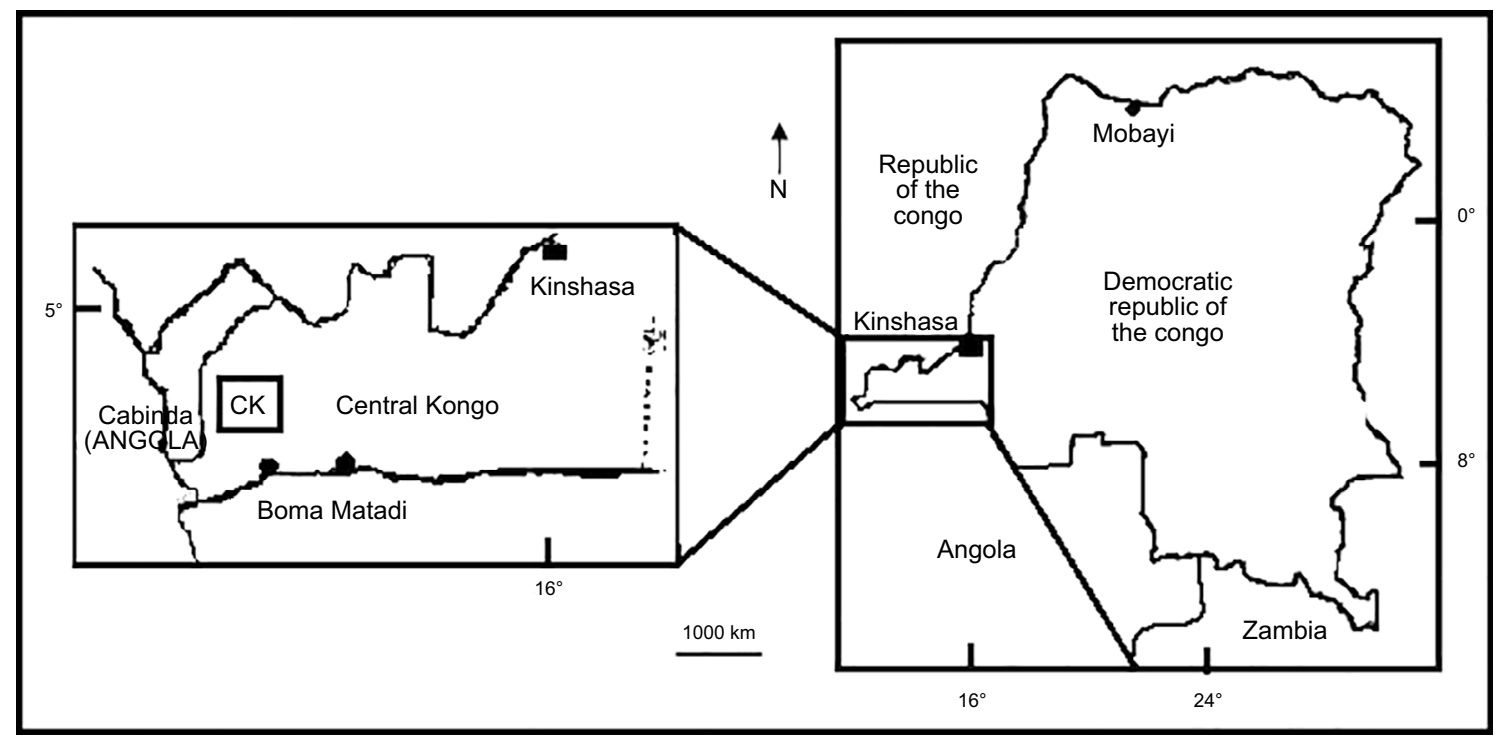

Fig. 1 Geological location of CK oil shale

Table 1 Rock-Eval parameters and chemical analysis of the OM in CK oil shale (Bouamoud et al. 2018)

\begin{tabular}{|c|c|c|c|}
\hline \multicolumn{4}{|c|}{ Rock-Eval parameters } \\
\hline \multicolumn{3}{|c|}{ Total organic carbon (TOC, wt \%) } & 10.77 \\
\hline \multicolumn{3}{|c|}{ Volatile hydrocarbon (HC) content (S1, mg HC/g rock) } & 2.7 \\
\hline \multicolumn{3}{|c|}{ Remaining HC generative potential (S2, mg HC/g rock) } & 80.4 \\
\hline \multicolumn{3}{|c|}{ Hydrogen index (HI, mg HC/g TOC) } & 746 \\
\hline \multicolumn{3}{|c|}{ Oxygen index (OI, $\mathrm{mg} \mathrm{CO}_{2} / \mathrm{g}$ TOC) } & 13 \\
\hline \multicolumn{3}{|c|}{$T_{\max }$, temperature at maximum amount of organic S2 hydrocarbons, ${ }^{\circ} \mathrm{C}$} & 438 \\
\hline \multicolumn{4}{|c|}{ Elemental analysis, wt \% } \\
\hline $\mathrm{C}$ & $\mathrm{H}$ & $\mathrm{N}$ & S \\
\hline \multirow{2}{*}{$\begin{array}{l}10.86 \\
\text { Type }\end{array}$} & 1.55 & 0.25 & 0.69 \\
\hline & & & \\
\hline
\end{tabular}

$\mathrm{H} / \mathrm{C}$ molar ratio (1.71), which corresponded to a sapropelic $\mathrm{OM}$ with type I kerogen. These findings were corroborated by the high value of hydrogen index $(\mathrm{HI}=746 \mathrm{mgHC} / \mathrm{g}$ TOC) and low value of oxygen index $\left(\mathrm{OI}=13 \mathrm{mgCO}_{2} / \mathrm{g}\right.$ TOC). The $\mathrm{S} 1$ parameter which was equal to $2.7 \mathrm{mgHC} / \mathrm{g}$ rock showed a low content of organic volatiles like bitumen. From these results, we can conclude that the shale rock studied presents a very promising petroleum potential and could be of significant commercial interest by comparing with other reported oil shales (Tissot and Welte 1984; Muhammad et al. 2011).

\subsection{Characterization}

X-ray diffraction (XRD) analysis was performed at room temperature using a Shimadzu 6100 diffractometer equipped with a copper anticathode $\left(\lambda_{\mathrm{CuK \alpha}}=1.541838 \AA\right)$ with a step scan of $0.02{ }^{\circ} \mathrm{s}^{-1}$, from 5 to $70\left({ }^{\circ} 2 \theta\right)$ and at $(40 \mathrm{kV}$ and $30 \mathrm{~mA}$ ). The identification of minerals in the samples was performed by comparing the obtained XRD patterns with those of the Joint Committee on Powder Diffraction Standards (JCPDS-ICDD) database. Fourier-transform infrared (FTIR) spectroscopy was carried out on a Jasco FT/IR 4600 spectrometer equipped with ATR (Pro One) module. FTIR spectra of the sample were obtained at $4 \mathrm{~cm}^{-1}$ resolution and collected in the range of $4000-400 \mathrm{~cm}^{-1}$. Simultaneous thermogravimetry/differential thermal analysis (TG/ DTA) was carried out using Labsys ${ }^{\mathrm{TM}}$ Evo (1F) SETARAM equipment. ICTAC kinetics committee recommendations for collecting experimental data and performing kinetics computations were used to evaluate the kinetic parameters (Vyazovkin et al. 2011, 2014). The thermal analysis system was standardized for temperature reading with reference 
metals of $99.99 \%$ purity to calibrate the microbalance by minimizing the buoyancy effects for better estimation of mass changes. The pyrolysis experiments were performed with a mass of $10 \mathrm{mg}( \pm 0.1 \mathrm{mg})$ of oil shale from room temperature to $1000{ }^{\circ} \mathrm{C}$ at different heating rates of $5,10,15$ and $20{ }^{\circ} \mathrm{C} \mathrm{min}^{-1}$ and under a nitrogen flow of $45 \mathrm{~mL} \mathrm{~min}^{-1}$. The mass of sample was placed in alumina pan with well dispersion and low depth to reduce heat and mass transfers. The thermal experiments were performed in triplicate to ensure repeatability and reproducibility of the obtained data.

\section{Results and discussion}

\subsection{XRD analysis}

The oil shale is a complex mixture of organic and mineral substances forming a very hard and nonporous material. The XRD pattern of the CK oil shale and its calcined form at $900{ }^{\circ} \mathrm{C}$ (CK 900) are displayed in Fig. 2. The CK oil shale is found to be predominantly containing quartz with main observed diffraction peaks corresponding to JCPDS Card file No. 01-079-1910. Small amounts of clay minerals, such as montmorillonite, illite and muscovite, were also detected which are indicative of a great hydrocarbon potential of the source rock (Wei et al. 2006). On the other hand, no traces of carbonate minerals such as calcite and dolomite were detected. This result is rarely found in known oil shales, but similar to those of Puertollano Spanish oil shale and Arbaa Ayacha Moroccan oil shale (Moine et al. 2018; Torrente and Galán 2001). Additionally, a broad continuum is observed in the XRD pattern, which is certainly due to the presence of an amorphous phase, corresponding to the complex OM in oil shale (Altun et al. 2009). The appearance of pyrite at 26.18 and $33.32^{\circ}$ is frequently observed in various carbon-rich

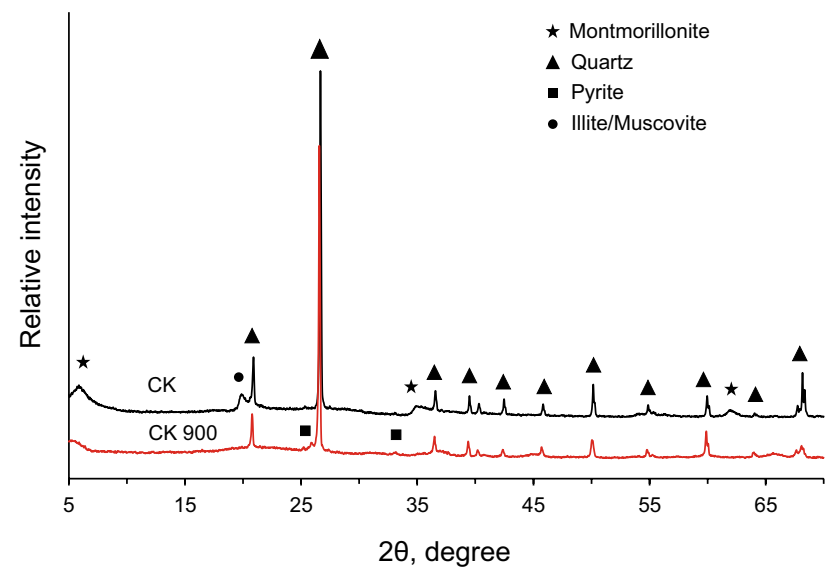

Fig. 2 XRD patterns of $\mathrm{CK}$ oil shale and its calcined form at $900{ }^{\circ} \mathrm{C}$ (CK 900) sedimentary rocks (Gai et al. 2014) and identified by SEM microscopy in our previous report (Bouamoud et al. 2018). The presence of pyrite in CK oil shale indicates the anoxic environment of the source rock, in agreement with marine or lacustrine deposition (Dyni 2003). The calcined CK oil shale at $900{ }^{\circ} \mathrm{C}$ (CK 900) under air atmosphere is mostly composed of quartz with the subsistence of pyrite. At high temperature, clay minerals are destroyed into oxides and $\mathrm{OM}$ volatilizes.

\subsection{FTIR-ATR spectroscopy}

FTIR spectra of CK and CK 900 samples are shown in Fig. 3. As can be seen, the CK sample exhibits a complex spectrum formed by the superposition of bands due to the $\mathrm{OM}$ and to the mineral matrix. Therefore, the $\mathrm{OM}$ was identified by the main unsaturated and saturated aliphatic $\mathrm{C}-\mathrm{H}$ absorption bands around 2930, 2800 and $1455 \mathrm{~cm}^{-1}$, revealing the dominance of sapropelic kerogen (Solomon and Miknis 1980). The existence of aromatic compounds is excluded because of the absence of their characteristic narrow band at about $3000 \mathrm{~cm}^{-1}$ (Alstadt et al. 2012). On the other side, the occurrence of small shoulder at $1715 \mathrm{~cm}^{-1}$ indicates the probable presence of carbonyl kinds (Bouamoud et al. 2018). The mineral matter was revealed by the absorption bands at 3703 and $3265 \mathrm{~cm}^{-1}$ which are assigned to $\mathrm{OH}$ groups linked to $\mathrm{Si}$ and $\mathrm{Al}$ of clays. Other absorption bands which appear around 3700 and $1630 \mathrm{~cm}^{-1}$ were attributed to internal water molecules of mineral clays (Palayangoda and Nguyen 2012). The multitude of bands observed in the region $1125-420 \mathrm{~cm}^{-1}$ were assigned to different vibration $\mathrm{Si}-\mathrm{O}$ modes of quartz (Palayangoda and Nguyen 2012). The absence of carbonate absorption bands $\left(\mathrm{CO}_{3}{ }^{2-}\right)$ at $1400 \mathrm{~cm}^{-1}$ confirms the results of the XRD analysis described above. The FTIR analysis results show that CK oil shale contains $\mathrm{OM}$ with dominance of aliphatic chains

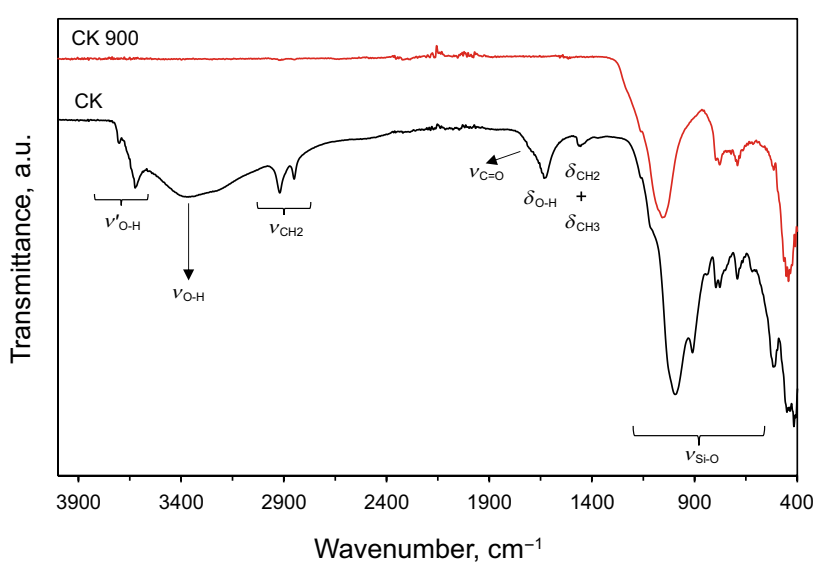

Fig. 3 FTIR-ATR spectra of CK oil shale and its calcined form at $900{ }^{\circ} \mathrm{C}(\mathrm{CK}$ 900) 
(type I kerogen) and corroborates our previous Rock-Eval analysis (Table 1).

As for the calcined sample of CK oil shales (CK 900), the FTIR spectrum shows only the absorption bands due to $\mathrm{Si}-\mathrm{O}$ and $\mathrm{Al}-\mathrm{O}$. However, a slight shift of bands toward high frequencies is observed. This is due to the structural arrangement of silica and alumina after the thermal degradation of organic matter and complete dehydroxylation of clay minerals (Bouamoud et al. 2018).

\subsection{Thermal analysis}

Figure 4 shows the thermal behavior of CK sample from room temperature up to $1000{ }^{\circ} \mathrm{C}$, at heating rate of $10{ }^{\circ} \mathrm{C} \mathrm{min}{ }^{-1}$ under nitrogen gas flow $\left(45 \mathrm{~mL} \mathrm{~min}^{-1}\right)$ and with initial mass of $10.0 \pm 0.1 \mathrm{mg}$. The presented TG, derivative TG (DTG) and DTA profiles show three mass losses. At temperature less than $200{ }^{\circ} \mathrm{C}$, the observed mass loss of about $4 \%$ and its corresponding endothermic peak are attributed to the removal of moisture as well as water molecules associated with the mineral matrix. The second and main mass loss occurring between 300 and $550{ }^{\circ} \mathrm{C}$, evaluated at $12.5 \%$ and accompanied by an endothermic effect in DTA, corresponds to the pyrolysis of kerogen present in oil shale to form oil, gas and residual carbon (Yan et al. 2013). This second stage is considered as the important pyrolysis step in processing oil shale. The temperature corresponding to the maximum pyrolysis rate and evaluated at $469{ }^{\circ} \mathrm{C}$ is similar to Kentucky and Green River oil shales (Maaten et al. 2016), but lower than many world oil shales (Janković 2013). According to the literature, low maximum decomposition temperature informs about the nature of OM and probably indicates a high kerogen reactivity in agreement with type I kerogen (Maaten et al. 2016). In the temperature range between 550 and $650{ }^{\circ} \mathrm{C}$, the low mass loss observed is assigned to the decomposition of pyrite contained in CK oil shale (Chen et al. 2000; Gai et al. 2014). The absence

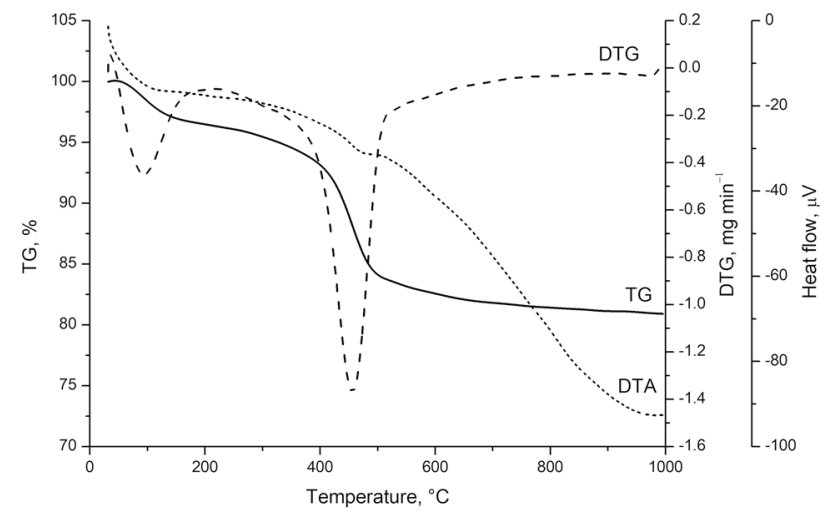

Fig. 4 Pyrolysis profiles of $\mathrm{CK}$ oil shale at heating rate of $10{ }^{\circ} \mathrm{C}$ $\min ^{-1}$ of distinct mass loss beyond $600{ }^{\circ} \mathrm{C}$ justifies the absence of carbonates and confirms the XRD and FTIR characterization results.

\subsection{Pyrolysis kinetics}

\subsubsection{Theoretical basis}

The general theoretical basis of thermal decomposition kinetics in solid state is expressed by the Arrhenius equation as follows (Khawam and Flanagan 2006; Vyazovkin et al. 2011):

$\frac{\mathrm{d} \alpha}{\mathrm{d} t}=k f(\alpha)=A \cdot \exp \left(\frac{-E_{\mathrm{a}}}{R T}\right) f(\alpha)$

where $\alpha$ is the reacted fraction, expressed as $\alpha=\left(m_{0}-m_{t}\right) /\left(m_{0}-m_{\infty}\right), k$ is the rate constant, $E_{\text {a }}$ $\left(\mathrm{kJ} \mathrm{mol}^{-1}\right)$ is the apparent activation energy, and $A$ $\left(\mathrm{min}^{-1}\right)$ is the pre-exponential factor, $R$ is the gas constant $\left(R=8.314 \mathrm{~J} \mathrm{~mol}^{-1} \mathrm{~K}^{-1}\right)$ and $f(\alpha)$ is the reaction model function that gives crucial information about the mechanism. The most known functions $f(\alpha)$ used in solid-state kinetics as well as their corresponding integral forms $g(\alpha)$ are recapitulated in Table 2.

The combination $A, E_{a}$ and $f(\alpha)$ is called the kinetic triplet. In case of non-isothermal modes, the temperature varies at a constant rate $\beta$, given by $\beta=\mathrm{d} T / \mathrm{d} t$. Equation (1) can then be transformed into:

$\frac{\mathrm{d} \alpha}{\mathrm{d} T}=\frac{A}{\beta} \cdot \exp \left(\frac{-E_{\mathrm{a}}}{R T}\right) f(\alpha)$

The function $g(\alpha)$ can be obtained by integrating Eq. (2) as follows:

$g(\alpha)=\int_{0}^{\alpha} \frac{d \alpha}{f(\alpha)}=\frac{A}{\beta} \int_{T_{0}}^{T} \exp \left(-\frac{E}{R T}\right) \mathrm{d} T \approx \frac{A E}{\beta R} p(x)$

where $x_{\infty}=E / R T$ and $p(x)$ is the temperature integral, with $p(x)=\int_{x}^{\infty} \frac{e^{-x}}{x^{2}} \mathrm{~d} x$

The function $p(x)$ has no analytical solutions but is solved using different mathematical approximation methods (Flynn 1997).

3.4.1.1 Determination of apparent activation energy $E_{a}$ According to ICTAC recommendations, the most accurate procedure to determine the activation energy in solid-state kinetics is the isoconversional method, which enables the calculation of activation energy without prior knowledge about the reaction model (Farjas and Roura 2011; Vyazovkin et al. 2011). This method is based on the isoconversional principle which states the linear depend- 
Table 2 Solid-state reaction functions $f(\alpha)$ and their integral forms $g(\alpha)$

\begin{tabular}{|c|c|c|c|}
\hline Reaction models & Symbol & $f(\alpha)$ & $g(\alpha)$ \\
\hline \multicolumn{4}{|c|}{ Chemical process or mechanism non-invoking equations } \\
\hline First-order & F1 & $(1-\alpha)^{1}$ & $-\ln (1-\alpha)$ \\
\hline Second-order & $\mathrm{F} 2$ & $(1-\alpha)^{2}$ & $(1-\alpha)^{-1}-1$ \\
\hline Three-half order & $\mathrm{F} 3 / 2$ & $(1-\alpha)^{3 / 2}$ & $2\left[(1-\alpha)^{-1 / 2}-1\right]$ \\
\hline Third-order & F3 & $(1-\alpha)^{3}$ & {$\left[(1-\alpha)^{-2}-1\right] / 2$} \\
\hline$n$th order $(n \neq 1)$ & Fn & $(1-\alpha)^{n}$ & {$\left[1-(1-\alpha)^{1-n}\right] /(1-n)$} \\
\hline \multicolumn{4}{|l|}{ Acceleratory rate equations } \\
\hline Power law & $\mathrm{P} 2$ & $2 \alpha^{1 / 2}$ & $\alpha^{1 / 2}$ \\
\hline Power law & $\mathrm{P} 3$ & $3 \alpha^{2 / 3}$ & $\alpha^{1 / 3}$ \\
\hline Power law & $\mathrm{P} 4$ & $4 \alpha^{3 / 4}$ & $\alpha^{1 / 4}$ \\
\hline \multicolumn{4}{|l|}{ Phase boundary reaction } \\
\hline Contracting area & $\mathrm{R} 2$ & $2(1-\alpha)^{1 / 2}$ & $1-(1-\alpha)^{1 / 2}$ \\
\hline Contracting volume & $\mathrm{R} 3$ & $3(1-\alpha)^{2 / 3}$ & $1-(1-\alpha)^{1 / 3}$ \\
\hline \multicolumn{4}{|l|}{ Diffusion mechanism } \\
\hline One-dimensional diffusion & D1 & $1 / 2 \alpha$ & $\alpha^{2}$ \\
\hline Two-dimensional diffusion & D2 & $1 /-\ln (1-\alpha)$ & {$[(1-\alpha) \ln (1-\alpha)]+\alpha$} \\
\hline Three-dimensional diffusion & D3 & $3(1-\alpha)^{2 / 3} /\left[2\left(1-(1-\alpha)^{1 / 3}\right)\right]$ & {$\left[1-(1-\alpha)^{1 / 3}\right]^{2}$} \\
\hline Ginstling-Brounstein & D4 & $3 / 2\left[(1-\alpha)^{-1 / 3}-1\right]$ & $1-(2 \alpha / 3)-(1-\alpha)^{2 / 3}$ \\
\hline \multicolumn{4}{|c|}{ Nucleation and growth rate equations } \\
\hline Avrami-Erofeev & A2 & $2(1-\alpha)[-\ln (1-\alpha)]^{1 / 2}$ & {$[-\ln (1-\alpha)]^{1 / 2}$} \\
\hline Avrami-Erofeev & A3 & $3(1-\alpha)[-\ln (1-\alpha)]^{2 / 3}$ & {$[-\ln (1-\alpha)]^{1 / 3}$} \\
\hline Avrami-Erofeev & A4 & $4(1-\alpha)[-\ln (1-\alpha)]^{3 / 4}$ & {$[-\ln (1-\alpha)]^{1 / 4}$} \\
\hline
\end{tabular}

ence between the reaction rate and temperature at constant conversion degree. Furthermore, it has the advantage to detect the presence of eventual complicated processes (Moine et al. 2016). In this study, the iterative form of the integral methods of OzawaFlynn-Wall (OFW) and Kissinger-Akahira-Sunose (KAS) was used to calculate the apparent activation energy as function of the conversion degree $\alpha$.

The iterative integral methods are used to allow more precise approximation of the temperature integral [Eq. (3)]. These methods assume that in a slight variation in temperature, the corresponding activation energy is almost constant (Deng et al. 2009). Among the most used, we find:

\section{(i) Iterative Ozawa-Flynn-Wall method}

The Ozawa-Flynn-Wall method (OFW) is based on Doyle's approximation to solve the temperature integral (Cai and Chen 2012; Flynn and Wall 1966). Rearrangement of Eq. (3) yields the following expression:

$\ln (\beta)=\ln \left(\frac{0.0048 A_{\alpha} E_{\alpha}}{R g(\alpha)}\right)-1.052\left(\frac{E_{\alpha}}{R T_{\alpha, \beta}}\right)$

Its iterative form IT-OFW is written as follows: $\ln \left(\frac{\beta}{H(x)}\right)=\ln \left(\frac{0.0048 A_{\alpha} E_{\alpha}}{\operatorname{Rg}(\alpha)}\right)-1.052\left(\frac{E_{\alpha}}{R T_{\alpha, \beta}}\right)$

where $H(x)=\frac{\exp (-x) h(x) / x^{2}}{0.0048 \exp (-1.052 x)}$

(ii) Iterative Kissinger-Akahira-Sunose method

The Kissinger-Akahira-Sunose method (KAS) is based on Murray and White's approximation to approach the temperature integral (Cai and Chen 2012; Liu et al. 2009). After rearrangement of Eq. (3), the KAS method can be written as follows:

$\ln \left(\frac{\beta}{T_{\alpha, \beta}^{2}}\right)=\ln \left(\frac{A_{\alpha} R}{E_{\alpha} g(\alpha)}\right)-\frac{E_{\alpha}}{R T_{\alpha, \beta}}$

Its iterative form IT-KAS can be expressed as:

$\ln \left(\frac{\beta}{h(x) T_{\alpha, \beta}^{2}}\right)=\ln \left(\frac{A_{\alpha} R}{E_{\alpha} g(\alpha)}\right)-\frac{E_{\alpha}}{R T_{\alpha, \beta}}$

where $h(x)=\frac{x^{4}+18 x^{3}+86 x^{2}+96 x}{x^{4}+20 x^{3}+120 x^{2}+240 x+120}$

Plotting the left side of Eq. (5), $\ln (\beta / H(x))$ versus $(1 / T)$, and of Eq. (7), $\ln \left(\beta / h(x) T^{2}\right)$ versus $(1 / T)$, at each conversion 
degree $\alpha$, leads to an estimate activation energy $E_{\alpha}$ which is deduced from the slope of the obtained straight lines.

\section{(iii) Iteration procedure}

The iteration procedure is realized by assuming that $h(x)=1$ or $H(x)=1$ to estimate the initial value of activation energy $E_{\alpha, 1}$. The energy calculation using the isoconversional methods gives then the value of $E_{\alpha, 1}$ corresponding to the conventional energy of the integral methods. This energy is then used to calculate new values of $h(x)$ and $H(x)$ and thus $E_{\alpha, 2}$. This operation is repeated continuously by replacing $E_{\alpha, i}$ with $E_{\alpha, j}$ until $\left|E_{\alpha, i}-E_{\alpha, j}\right|<0.01 \mathrm{~kJ} \mathrm{~mol}^{-1}$. The last value of $E_{\alpha, i}$ is then the exact value of activation energy of the pyrolysis process.

3.4.1.2 Reaction model determination The conversion function $f(\alpha)$ is the mathematical and theoretical description of the decomposition reaction mechanism (Table 2). Different methods were developed to evaluate the kinetic model describing the experimental data (Vyazovkin et al. 2011), upon which is the Coats-Redfern method that was developed from Eq. (3) using the temperature integral approximation of Coats and Redfern (1964) and different reaction models $f(\alpha)$. It is expressed as:

$\ln \left(\frac{g(\alpha)}{T^{2}}\right)=\ln \left(\frac{A R}{\beta E}\right)-\frac{E}{R T}$

The plot $\ln \left[g(\alpha) / T^{2}\right]$ against $1 / T$ should give a straight line if the proposed reaction model corresponds to the pyrolysis mechanism involved.

In order to refine the kinetic parameters obtained by Coats-Redfern method, the direct Arrhenius plot method was used. Considering the general kinetic equation and after rearrangement, Eq. (2) becomes:

$\ln \left(\frac{1}{f(\alpha)} \frac{\mathrm{d} \alpha}{\mathrm{d} T}\right)=\ln \frac{A}{\beta}-\frac{E}{R T}$

The linear plot of Eq. (9), $\ln \left[\frac{1}{f(\alpha)} \frac{\mathrm{d} \alpha}{\mathrm{d} T}\right]=f\left(\frac{1}{T}\right)$, is obtained after supposing the reaction model $f(\alpha)$. The slope and intercept will provide the activation energy $E$ and the pre-exponential factor $A$, respectively. The most probable reaction model $f(\alpha)$, which describes the pyrolysis process, will have an activation energy near the one obtained from the iterative isoconversional methods.

3.4.1.3 Pre-exponential factor determination The preexponential factor $A$ value was estimated using the equation proposed by Málek (1989) [Eq. (10)] and compared to the values obtained by Arrhenius plot method at each heating rate:
$A=\frac{-\beta E_{\alpha}}{R T_{\max }^{2} f^{\prime}\left(\alpha_{\max }\right)} \exp \left(\frac{E_{\alpha}}{R T_{\max }}\right)$

where $T_{\max }$ is the temperature and $\alpha_{\max }$ is the conversion degree at the maximum reaction rate.

3.4.1.4 Thermodynamic parameters The thermodynamic parameters of CK oil shale pyrolysis were estimated using the equation developed by the transition state theory (Font and García 1995). They are expressed using the following equations:

$\Delta S^{*}=R \ln \left(\frac{A h}{e \chi k_{\mathrm{B}} T_{\mathrm{p}}}\right)$

$\Delta H^{*}=E_{\mathrm{a}}-R T_{\mathrm{p}}$

$\Delta G^{*}=\Delta H^{*}-T_{\mathrm{p}} \Delta S^{*}$

where $e=2.7183$ is the Neper Number, $\chi$ is the transmission factor, which is equal to unity for monomolecular reactions, $k_{\mathrm{B}}$ is the Boltzmann constant $\left(1.381 \times 10^{-23} \mathrm{~J} \mathrm{~K}^{-1}\right), h$ is the Plank constant $\left(6.626 \times 10^{-34} \mathrm{~J} \mathrm{~s}\right), T_{\mathrm{p}}$ is the temperature at the maximum reaction rate in DTA curve and $E_{\mathrm{a}}$ is the average activation energy obtained from IT-KAS method.

\subsubsection{Thermal kinetics of CK oil shale}

Kinetic study of CK oil shale pyrolysis was conducted for the main thermal step corresponding to the OM decomposition as illustrated in Fig. 4. Thermal measurements were realized under non-isothermal conditions using four sets of heating rates $\left(5,10,15\right.$ and $\left.20^{\circ} \mathrm{C} \mathrm{min}^{-1}\right)$, in accordance with ASTM standard (E11) and ICTAC kinetics recommendations. The obtained curves of conversion degree $\alpha$ and

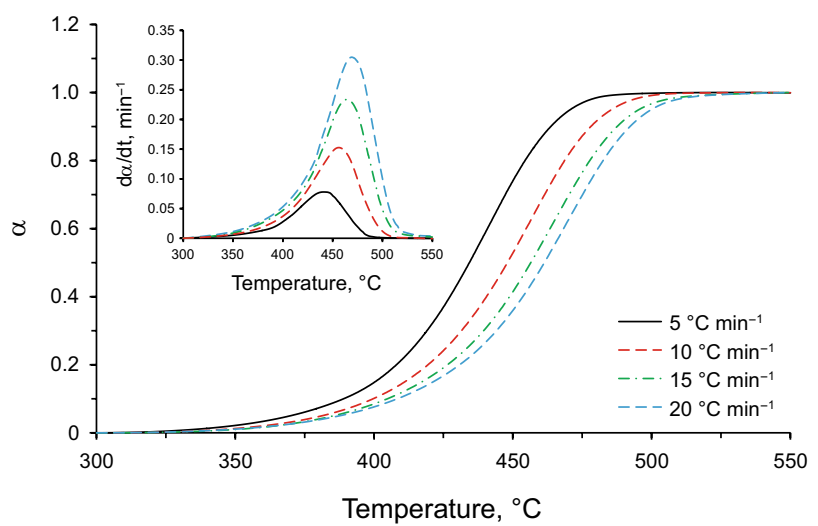

Fig. 5 Conversion curves $\alpha=f(T)$ and $\mathrm{d} a / \mathrm{d} t=f(T)$ of CK oil shale at different heating rates 
Table 3 Thermal characteristics of CK oil shale as function of heating rates

\begin{tabular}{llll}
\hline$B,{ }^{\circ} \mathrm{C} \mathrm{min}$ & \\
\hline 5 & $T_{\text {onset }},{ }^{\circ} \mathrm{C}$ & $T_{\text {offset }},{ }^{\circ} \mathrm{C}$ & $T_{\max },{ }^{\circ} \mathrm{C}$ \\
10 & 391.7 & 481.0 & 440.2 \\
15 & 401.4 & 497.6 & 456.0 \\
20 & 406.7 & 506.0 & 464.2 \\
\hline
\end{tabular}

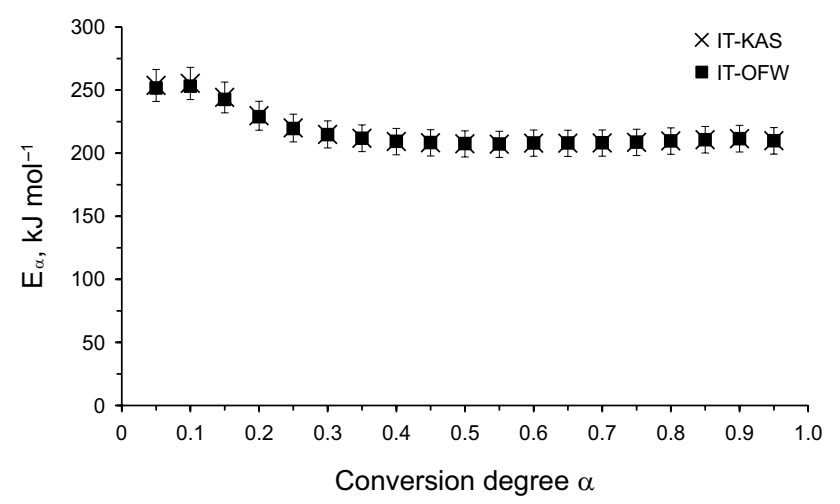

Fig. 6 Variation in activation energy of CK oil shale as function of conversion degree $\alpha$

reaction rate $\mathrm{d} \alpha / \mathrm{d} t$ as function of temperature are shown in Fig. 5. As can be seen, all thermal curves present a single thermal transformation corresponding to the decomposition process of OM to hydrocarbons. Similar trend of singlestep pyrolysis was also observed in other oil shales, such as Green River oil shale and Kentucky oil shale (Maaten et al. 2016, 2017; Tiwari and Deo 2012b). The single-step mechanism in pyrolysis of oil shales is uncommon and related to the type of kerogen (Williams and Ahmad 2000). In fact, the type I kerogen which is predominantly composed of aliphatic hydrocarbons can lead to the same thermal behavior, while the type II and type III kerogens exhibit complex behaviors because of the additional presence of bitumen and aromatics in oil shales (Bai et al. 2015a; Moine et al. 2018). The displacement of the thermal curves toward higher temperatures when increasing the heating rates is a common result of several previous studied world's oil shales (Bai et al. 2015a; Li and Yue 2004). This is due to the temperature gradient inside and outside the particles of $\mathrm{OM}$, which is lower at low heating rates and higher at longer exposure of sample to a particulate temperature (Sánchez-Rodríguez et al. 2014), (Table 3).

3.4.2.1 Activation energy determination The iterative isoconversional methods IT-OFW and IT-KAS [Eqs. (5) and (7)] were used to evaluate the distribution of apparent activation energy during the pyrolysis process. The $\left(E_{\alpha}-\alpha\right)$ curves illustrated in Fig. 6 show comparable behavior for both iterative methods. In the conversion range between 0.2 and 0.8 , the apparent activation energy is practically constant and its variation does not exceed $5 \%$. This result reflects the presence of a unique OM degradation process, characterized by a single kinetic triplet. A similar finding was also obtained on Huadian oil shale (Qing et al. 2009). The average activation energy corresponding to the $\mathrm{OM}$ pyrolysis process of $\mathrm{CK}$ oil shale is estimated to be $211.5 \pm 4.7 \mathrm{~kJ} \mathrm{~mol}^{-1}$. This value is consistent with the energies obtained during the type I kerogen pyrolysis of the Green River, Colorado and Huadian oil shales which were evaluated to be 201, 219.4 and $231 \mathrm{~kJ} \mathrm{~mol}^{-1}$, respectively (Campbell et al. 1978; Han et al. 2015; Maaten et al. 2017).

3.4.2.2 Determination of reaction mechanism The reaction mechanism is a description of the pathway by which the decomposition reaction occurs. It is generally expressed by a theoretical and mathematical equation called the reaction model. Hence, for CK oil shale, the reaction model was determined using the Coats-Redfern procedure [Eq. (6)]. The linear regression of $\ln \left[g(\alpha) / T^{2}\right]$ versus $(1 / T)$ for different heating rates gives the results summarized in Table 4.

Many reaction models show good correlation with the experimental data $\left(R^{2}=0.999\right)$, whereas the calculated activation energies are different between the supposed models. When comparing these values with the average activation energy obtained from the isoconversional IT-KAS method, evaluated to be $211.5 \mathrm{~kJ} \mathrm{~mol}^{-1}$, it enables identification of the suitable kinetic model which has the closest value to the isoconversional value. Therefore, since the IT-KAS activation energy is found between the mean energy values of $F 1$ and $F 2$ models $\left(164.1 \mathrm{~kJ} \mathrm{~mol}^{-1}\right.$ and $247.9 \mathrm{~kJ} \mathrm{~mol}^{-1}$, respectively) compared to other models (Table 4), the mechanism that describes the pyrolysis kinetics of CK oil shale is more probably following the $F n$ model, with $n$ value ranging from 1 to 2 . This $F n$ model has also been reported to describe the mechanism of many oil shales' pyrolysis or combustion (Kök and Pamir 2000; Kuang et al. 2018; Ma and Li 2018).

To obtain the exact value of $n$, the Arrhenius linear plot method (Eq. (9)) was used, with the plot of $\ln \left(\frac{1}{f(\alpha)} \frac{\mathrm{d} \alpha}{\mathrm{d} T}\right)$ versus $1000 / T$ (Fig. 6). According to the results obtained by Coats-Redfern method, the reaction model $f(\alpha)$ used was $(1-\alpha)^{n}$ with $n$ estimated in the range of 1 and 2 . The reliable and precise reaction order $n$ was assumed to generate the activation energy equal to that of IT-KAS isoconversional method. Table 5 displays the calculated values of $E$ and $\ln A$ of CK oil shale pyrolysis as function of $n$ using the experimental data. Figure 7 shows the Arrhenius linear curves obtained with the exact value of the reaction order $n$ at which the slope gives an activation energy equal to that estimated by the IT-KAS method. The obtained results at different 
Table 4 Coats-Redfern parameters for CK oil shale pyrolysis kinetics

\begin{tabular}{|c|c|c|c|c|c|c|c|c|}
\hline \multirow[t]{2}{*}{ Model } & \multicolumn{2}{|l|}{$5^{\circ} \mathrm{C} \min ^{-1}$} & \multicolumn{2}{|l|}{$10^{\circ} \mathrm{C} \min ^{-1}$} & \multicolumn{2}{|l|}{$15^{\circ} \mathrm{C} \min ^{-1}$} & \multirow{2}{*}{$\begin{array}{l}20^{\circ} \mathrm{C} \mathrm{min}^{-1} \\
E \mathrm{~kJ} \mathrm{~mol}^{-1}\end{array}$} & \multirow{2}{*}{$\begin{array}{l}\text { Average } \\
E, \mathrm{~kJ} \mathrm{~mol}^{-1}\end{array}$} \\
\hline & $E, \mathrm{~kJ} \mathrm{~mol}^{-1}$ & $R^{2}$ & $E, \mathrm{~kJ} \mathrm{~mol}^{-1}$ & $R^{2}$ & $E, \mathrm{~kJ} \mathrm{~mol}^{-1}$ & $R^{2}$ & & \\
\hline F1 & 166.5 & 0.9999 & 163.8 & 0.9994 & 162.2 & 0.9992 & 163.7 & 164.1 \\
\hline $\mathrm{F} 2$ & 251.7 & 0.9894 & 247.4 & 0.9855 & 245.2 & 0.9850 & 247.3 & 247.9 \\
\hline F3 & 357.8 & 0.9717 & 351.5 & 0.9657 & 348.4 & 0.9651 & 351.2 & 352.2 \\
\hline $\mathrm{P} 2$ & 46.5 & 0.9799 & 45.6 & 0.9849 & 45.0 & 0.9850 & 45.5 & 45.7 \\
\hline P3 & 27.1 & 0.9734 & 26.4 & 0.9797 & 26.0 & 0.9797 & 26.2 & 26.4 \\
\hline P4 & 17.4 & 0.9633 & 16.8 & 0.9715 & 16.4 & 0.9712 & 16.6 & 16.8 \\
\hline D1 & 221.5 & 0.9860 & 218.5 & 0.9897 & 216.5 & 0.9899 & 218.6 & 218.8 \\
\hline R2 & 132.8 & 0.9965 & 130.6 & 0.9983 & 129.4 & 0.9982 & 130.6 & 130.9 \\
\hline R3 & 143.3 & 0.9986 & 141.0 & 0.9995 & 139.7 & 0.9994 & 141.0 & 141.3 \\
\hline D2 & 255.4 & 0.9935 & 251.8 & 0.9959 & 249.6 & 0.9960 & 252.0 & 252.2 \\
\hline D3 & 298.5 & 0.9987 & 294.1 & 0.9996 & 291.5 & 0.9995 & 294.2 & 294.6 \\
\hline D4 & 269.6 & 0.9958 & 265.7 & 0.9977 & 263.4 & 0.9977 & 265.9 & 266.2 \\
\hline A2 & 77.3 & 0.9999 & 75.9 & 0.9994 & 75.0 & 0.9992 & 75.7 & 76.0 \\
\hline A3 & 47.6 & 0.9999 & 46.6 & 0.9993 & 46.0 & 0.9991 & 46.4 & 46.7 \\
\hline A4 & 32.8 & 0.9999 & 31.9 & 0.9992 & 31.4 & 0.9989 & 31.7 & 32.0 \\
\hline
\end{tabular}

Table 5 Arrhenius plot parameters of pyrolysis kinetics of CK oil shale

\begin{tabular}{|c|c|c|c|c|c|c|c|c|}
\hline \multirow[t]{2}{*}{$n$} & \multicolumn{2}{|l|}{$5^{\circ} \mathrm{C} \mathrm{min}^{-1}$} & \multicolumn{2}{|l|}{$10{ }^{\circ} \mathrm{C} \mathrm{min}-1$} & \multicolumn{2}{|l|}{$15^{\circ} \mathrm{C} \mathrm{min}-1$} & \multicolumn{2}{|l|}{$20{ }^{\circ} \mathrm{C} \min ^{-1}$} \\
\hline & $E, \mathrm{~kJ} \mathrm{~mol}^{-1}$ & $\ln A$ & $E, \mathrm{~kJ} \mathrm{~mol}^{-1}$ & $\ln A$ & $E, \mathrm{~kJ} \mathrm{~mol}^{-1}$ & $\ln A$ & $E, \mathrm{~kJ} \mathrm{~mol}^{-1}$ & $\ln A$ \\
\hline 1 & 172.6 & 27.4 & 176.7 & 28.2 & 176.6 & 28.3 & 179.9 & 28.9 \\
\hline 1.1 & 184.8 & 29.6 & 191.1 & 30.7 & 190.9 & 30.7 & 194.3 & 31.3 \\
\hline 1.2 & 197.0 & 31.7 & 205.5 & 33.2 & 205.2 & 33.2 & 206.1 & 33.3 \\
\hline 1.25 & 203.1 & 32.8 & 209.1 & 33.8 & 210.6 & 34.1 & 212.0 & 34.3 \\
\hline 1.3 & 209.2 & 33.9 & 219.9 & 35.7 & 219.5 & 35.6 & 223.1 & 36.2 \\
\hline 1.35 & 220.1 & 35.8 & 227.1 & 36.9 & 226.6 & 36.8 & 230.3 & 37.4 \\
\hline 1.4 & 227.4 & 37.1 & 234.3 & 38.1 & 233.8 & 38.0 & 237.5 & 38.7 \\
\hline
\end{tabular}

heating rates give an average reaction order equal to 1.275. Analogous results were found in the literature, such as for the pyrolysis of Brazilian kerogen oil shale with $n=1.23$ (Janković 2013) and Moroccan Rif oil shale with $n=1.07$ (Moine et al. 2016).

The pre-exponential factor values obtained by the Arrhenius linear plot method at different heating rates were compared to the calculated values using Eq. (10). The obtained values of $\ln A$ are close to each other for all heating rates (Table 6) and confirm the proposed reaction order model $F n(n=1.275)$. The mean value of $A$ was evaluated at 3.23 $10^{14}$, which is a high value that indicates the presence of "loose" complex process during pyrolysis (Cordes 1968). The same magnitude was observed for most world oil shales degradations (Janković 2013; Maaten et al. 2016; Moine et al. 2016). The high pre-exponential values were also found for the complex decomposition of polymeric organic macromolecules such as poly(tetrafluoroethene) and chitin (Genieva et al. 2010; Georgieva et al. 2012).

The comparison of kinetic parameters of $\mathrm{CK}$ oil shale with other type I kerogen oil shale is illustrated in Table 7. Although the pyrolysis kinetic approach of CK oil shale is different compared to other oil shale reported in the literature, the experimental kinetic parameters are in good agreement. From these results, it can be concluded that thermogravimetric pyrolysis is a useful complementary technique for studying the nature and composition of kerogen in oil shales.

3.4.2.3 Modeling of experimental data The above-obtained kinetic parameters at each heating rate were substituted in Eq. (1) to simulate the experimental reaction rate curves of $\mathrm{CK}$ oil shale pyrolysis. Figure 8 displays the plots of the experimental and the obtained theoretical data at different 

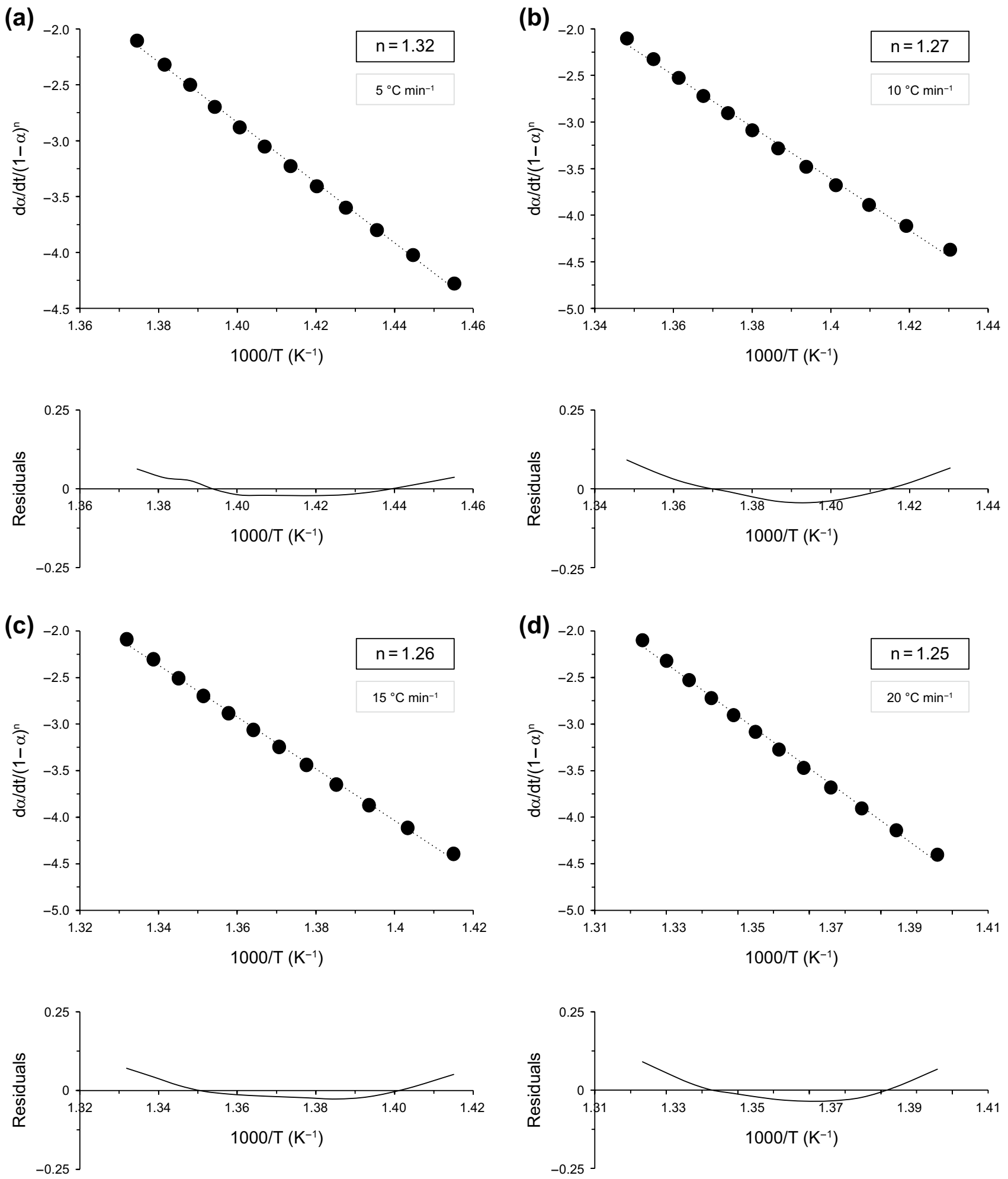

Fig. 7 Arrhenius linear plots of CK oil shale at different heating rates and their residuals

heating rates. Hence, the fitted curves show a general good agreement with experimental data in the range of $\alpha>0.2$, which correspond to major pyrolysis process of kerogen included in CK oil shale. On the other hand, the discrepancies observed at the beginning of pyrolysis process are more probably associated with the low amount of soluble 
Table 6 Pre-exponential factor of CK oil shale at different heating rates

\begin{tabular}{llllll}
\hline$b,{ }^{\circ} \mathrm{C} \min ^{-1}$ & 5 & 10 & 15 & 20 & Average value \\
\hline $\ln A$ (Arrhenius plot) & 34.30 & 34.23 & 34.25 & 34.27 & 34.26 \\
$\ln A$ (Eq. 10) & 34.29 & 33.48 & 33.07 & 32.83 & 33.41 \\
\hline
\end{tabular}

and volatile bitumen present in CK oil shale, in agreement with the Rock-Eval analysis. The kinetic triplet found by the methods used in this work leads to a satisfactory modeling of the experimental data of CK oil shale pyrolysis.

\subsection{Thermodynamic parameters}

The application of transition state theory to CK oil shale pyrolysis was performed through the estimation of thermodynamic parameters using Eqs. (11)-(13). The activation energy used was the mean value of IT-KAS method. The pre-exponential factor $A$ and reaction order $n$ were taken from the Arrhenius plot method. The obtained average results are summarized in Table 8 . The positive values of activated entropies $\Delta S^{*}$ indicate the presence of malleable activated complexes and large number of freedom degrees for rotation and vibration (Shannon 1964). The positive values of activated enthalpies $\Delta H^{*}$ are consistent with the endothermic effect observed in CK oil shale pyrolysis. However, the positive values of free Gibbs energies $\Delta G^{*}$ suggest thermodynamically stable nature of CK oil shale under atmosphere pressure and its decomposition occurs upon heating.

\section{Conclusion}

The physicochemical characterization of Central Kongo oil shale (CK) was carried out using XRD, FTIR and TG/DTA techniques and showed that it mainly consists of quartz and organic matter $(\mathrm{OM})$ with sapropelic chains (Type I kerogen). The non-isothermal pyrolysis of CK sample was investigated using thermogravimetric analysis, and the kinetic parameters were estimated using the iterative isoconversional IT-KAS and IT-OFW methods followed by the Coats-Redfern and Arrhenius plot methods. The main

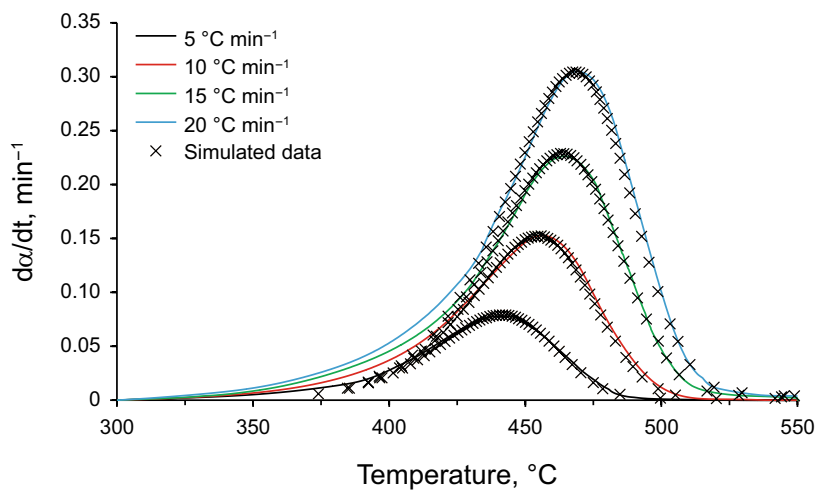

Fig. 8 Theoretical and experimental reaction rate curves of CK oil shale pyrolysis

Table 8 Thermodynamic parameters of CK oil shale pyrolysis

\begin{tabular}{|c|c|c|c|}
\hline $\mathrm{b},{ }^{\circ} \mathrm{C} \min ^{-1}$ & $\begin{array}{l}\Delta S^{*} \\
\mathrm{~J} \mathrm{~mol}^{-1} \mathrm{~K}^{-1}\end{array}$ & $\Delta G^{*}, \mathrm{~kJ} \mathrm{~mol}^{-1}$ & $\Delta H^{*}, \mathrm{~kJ} \mathrm{~mol}^{-1}$ \\
\hline 5 & 24.6 & 205.6 & 188.1 \\
\hline 10 & 17.7 & 205.5 & 192.6 \\
\hline 15 & 15.5 & 205.4 & 194.0 \\
\hline 20 & 11.6 & 205.3 & 196.7 \\
\hline Average & 17.3 & 205.5 & 192.9 \\
\hline
\end{tabular}

pyrolysis step was observed in the temperature range of $300{ }^{\circ} \mathrm{C}-550^{\circ} \mathrm{C}$ and characterized by a single mass loss of $12.5 \%$ which corresponds to degradation of type I kerogen. Using isoconversional methods, the apparent activation energy of the pyrolysis, evaluated by IT-KAS method, was found constant in the main range of conversion [0.2-0.8] and equal to $211.5 \pm 4.7 \mathrm{~kJ} \mathrm{~mol}^{-1}$, in compatibility with the type I kerogen. The pyrolysis mechanism of kerogen was estimated using Coats-Redfern followed by Arrhenius plot methods, and the results give a single kinetic triplet with $E \alpha=210.0 \mathrm{~kJ} \mathrm{~mol}^{-1}, \ln A=34.26$ and $f(\alpha)=(1-\alpha)^{1.275}$. These values are consistent with type I kerogen which is formed mainly by sapropelic chains. On the other hand, the thermodynamic parameters evaluated were fully correlated with the endothermic effect and the non-spontaneous nature of the CK oil shale during pyrolysis.

Table 7 Comparison of kinetics data of some type I kerogen oil shales

\begin{tabular}{lllll}
\hline Oil shale sample & $E, \mathrm{~kJ} \mathrm{~mol}^{-1}$ & Reaction order $n$ & Ln $A$ & References \\
\hline Green River oil shale & 201.0 & 1 & 32.41 & Maaten et al. (2017) \\
Colorado oil shale & 219.4 & 1 & 30.96 & Campbell et al. (1978) \\
Huadian oil shale & 231.0 & 1 & 36.79 & Han et al. (2015) \\
CK oil shale & 211.5 & 1.275 & 33.41 & This study \\
\hline
\end{tabular}


Acknowledgements This research was financially supported by University of Mohammed V-Morocco under the Project No. SCH 04/09 and Hassan II Academy of Science and Technology, Morocco.

Open Access This article is distributed under the terms of the Creative Commons Attribution 4.0 International License (http://creativeco mmons.org/licenses/by/4.0/), which permits unrestricted use, distribution, and reproduction in any medium, provided you give appropriate credit to the original author(s) and the source, provide a link to the Creative Commons license, and indicate if changes were made.

\section{References}

Alstadt KN, Katti DR, Katti KS. An in situ FTIR step-scan photoacoustic investigation of kerogen and minerals in oil shale. Spectrochim Acta Part A Mol Biomol Spectrosc. 2012;89:105-13. https://doi.org/10.1016/j.saa.2011.10.078.

Altun NE, Hwang JY, Hicyilmaz C. Enhancement of flotation performance of oil shale cleaning by ultrasonic treatment. Int $\mathbf{J}$ Miner Process. 2009;91(1-2):1-13. https://doi.org/10.1016/j. minpro.2008.10.003.

Bai F, Guo W, Lü X, Liu Y, Guo M, Li Q, et al. Kinetic study on the pyrolysis behavior of Huadian oil shale via non-isothermal thermogravimetric data. Fuel. 2015a;146:111-8. https://doi. org/10.1016/j.fuel.2014.12.073.

Bai F, Sun Y, Liu Y, Li Q, Guo M. Thermal and kinetic characteristics of pyrolysis and combustion of three oil shales. Energy Convers Manag. 2015b;97:374-81. https://doi.org/10.1016/j. enconman.2015.03.007.

Bai F, Sun Y, Liu Y, Guo M. Evaluation of the porous structure of Huadian oil shale during pyrolysis using multiple approaches. Fuel. 2017;187:1-8. https://doi.org/10.1016/j.fuel.2016.09.012.

Bouamoud R, El-Hamidi A, Halim M, Masamba RM, Nlandu RAK, Arsalane S. Mineralogical characterization and preliminary assessment of the hydrocarbon potential of sedimentary rock from the western part of the Central Kongo. Mediterr J Chem. 2018;7(2):93-104. https://doi.org/10.13171/mjc72/0180630203 0 -arsalane.

Cai J, Chen Y. Iterative linear integral isoconversional method: theory and application. Bioresour Technol. 2012;103(1):309-12. https://doi.org/10.1016/j.biortech.2011.10.008.

Cailteux JLH, Delpomdor FRA, Ndobani JPN. The Neoproterozoic West-Congo "schisto-calcaire" sedimentary succession from the Bas-Congo region (Democratic Republic of the Congo) in the frame of regional tentative correlations. Geol Belg. 2015; 18:126-46.

Campbell JH, Koskinas GH, Stout ND. Kinetics of oil generation from Colorado oil shale. Fuel. 1978;57(6):372-6. https://doi. org/10.1016/0016-2361(78)90176-X.

Chen H, Li B, Zhang B. Decomposition of pyrite and the interaction of pyrite with coal organic matrix in pyrolysis and hydropyrolysis. Fuel. 2000;79(13):1627-31. https://doi.org/10.1016/S0016 2361(00)00015-6.

Coats AW, Redfern JP. Kinetic parameters from thermogravimetric data. Nature. 1964;201(4914):68-9. https://doi. org/10.1038/201068a0.

Cordes HF. Preexponential factors for solid-state thermal decomposition. J Phys Chem. 1968;72(6):2185-9. https://doi.org/10.1021/ j100852a052.

Daly MC, Lawrence SR, DiemuTshiband K, Matouana B. Tectonic evolution of the cuvette centrale, Zaire. J Geol Soc. 1992;149(4):539-46. https://doi.org/10.1144/gsjgs.149.4.0539.
Delvaux D, Fernandez-Alonso M. Petroleum potential of the Congo basin. In: de Wit MJ, Guillocheau F, de Wit MCJ, editors. Geology and resource potential of the Congo Basin. Berlin: Springer; 2015. p. 370-91. https://doi.org/10.1007/978-3-642-29482-2.

Demirbas A. Conversion of oil shale to liquid hydrocarbons. Energy Sources Part A Recover Util Environ Eff. 2016;38(18):2698703. https://doi.org/10.1080/15567036.2015.1115925.

Deng C, Cai J, Liu R. Kinetic analysis of solid-state reactions: evaluation of approximations to temperature integral and their applications. Solid State Sci. 2009;11(8):1375-9. https://doi. org/10.1016/j.solidstatesciences.2009.04.009.

Dyni JR. Geology and resources of some world oil-shale deposits. Oil Shale. 2003;20(3):193-252.

Farjas J, Roura P. Isoconversional analysis of solid state transformations. J Therm Anal Calorim. 2011;105(3):767-73. https://doi. org/10.1007/s10973-011-1447-3.

Flynn JH. The 'Temperature integral'-its use and abuse. Thermochim Acta. 1997;300(1-2):83-92. https://doi.org/10.1016/S0040 -6031(97)00046-4.

Flynn JH, Wall LA. A quick, direct method for the determination of activation energy from thermogravimetric data. J Polym Sci Part B Polym Lett. 1966;4(5):323-8. https://doi.org/10.1002/ pol.1966.110040504.

Font R, García AN. Application of the transition state theory to the pyrolysis of biomass and tars. J Anal Appl Pyrolysis. 1995;35(2):249-58. https://doi.org/10.1016/0165-2370(95)00916 $-8$.

Gai R, Jin L, Zhang J, Wang J, Hu H. Effect of inherent and additional pyrite on the pyrolysis behavior of oil shale. J Anal Appl Pyrolysis. 2014;2014(105):342-7. https://doi.org/10.1016/j. jaap.2013.11.022.

Geng Y, Liang W, Liu J, Cao M, Kang Z. Evolution of pore and fracture structure of oil shale under high temperature and high pressure. Energy Fuels. 2017;31(10):10404-13. https://doi.org/10.1021/acs. energyfuels.7b01071.

Genieva SD, Vlaev LT, Atanassov AN. Study of the thermooxidative degradation kinetics of poly(tetrafluoroethene) using isoconversional calculation procedure. J Therm Anal Calorim. 2010;99(2):551-61. https://doi.org/10.1007/s10973-009-0191-4.

Georgieva V, Zvezdova D, Vlaev L. Non-isothermal kinetics of thermal degradation of chitosan. Chem Cent J. 2012;6(1):81-91. https:// doi.org/10.1186/1752-153X-6-81.

Han H, Zhong NN, Huang CX, Zhang W. Pyrolysis kinetics of oil shale from northeast China: implications from thermogravimetric and Rock-Eval experiments. Fuel. 2015;159:776-83. https://doi. org/10.1016/j.fuel.2015.07.052.

Janković B. The kinetic modeling of the non-isothermal pyrolysis of Brazilian oil shale: application of the Weibull probability mixture model. J Pet Sci Eng. 2013;111:25-36. https://doi.org/10.1016/j. petrol.2013.10.001.

Jiang H, Song L, Cheng Z, Chen J, Zhang L, Zhang M, et al. Influence of pyrolysis condition and transition metal salt on the product yield and characterization via Huadian oil shale pyrolysis. J Anal Appl Pyrolysis. 2015;112:230-6. https://doi.org/10.1016/j. jaap.2015.01.020.

Karabakan A, Yürüm Y. Effect of the mineral matrix in the reactions of oil shales: 1. Pyrolysis reactions of Turkish Göynük and US Green River oil shales. Fuel. 1998;77(12):1303-9. https://doi. org/10.1016/S0016-2361(98)00045-3.

Khawam A, Flanagan DR. Solid-state kinetic models: basics and mathematical fundamentals. J Phys Chem B. 2006;110(35):17315-28. https://doi.org/10.1021/jp062746a.

Khraisha YH, Shabib IM. Thermal analysis of shale oil using thermogravimetry and differential scanning calorimetry. Energy Convers Manag. 2002;43(2):229-39. https://doi.org/10.1016/S0196 -8904(01)00023-1. 
Kök MV, Pamir MR. Comparative pyrolysis and combustion kinetics of oil shales. J Anal Appl Pyrolysis. 2000;55(2):185-94. https:// doi.org/10.1016/S0165-2370(99)00096-0.

Kuang W, Lu M, Yeboah I, Qian G, Duan X, Yang J, et al. A comprehensive kinetics study on non-isothermal pyrolysis of kerogen from Green River oil shale. Chem Eng J. 2018. https://doi. org/10.1016/j.cej.2018.10.212.

Li S, Yue C. Study of different kinetic models for oil shale pyrolysis. Fuel Process Technol. 2004;85(1):51-61. https://doi.org/10.1016/ S0378-3820(03)00097-3.

Liu F, Liu XN, Wang Q. Examination of Kissinger's equation for solidstate transformation. J Alloys Compd. 2009;473(1-2):152-6. https ://doi.org/10.1016/j.jallcom.2008.05.103.

Ma Y, Li S. The mechanism and kinetics of oil shale pyrolysis at the presence of water. Carbon Resour Convers. 2018;14(1):47-64. https://doi.org/10.1101/112268.

Maaten B, Loo L, Konist A, Nesumajev D, Pihu T, Külaots I. Decomposition kinetics of american, chinese and estonian oil shales kerogen. Oil Shale. 2016;33(2):167-83. https://doi.org/10.3176/ oil.2016.2.05.

Maaten B, Loo L, Konist A, Pihu T, Siirde A. Investigation of the evolution of sulphur during the thermal degradation of different oil shales. J Anal Appl Pyrolysis. 2017;128:405-11. https://doi. org/10.1016/j.jaap.2017.09.007.

Maaten B, Loo L, Konist A, Siirde A. Mineral matter effect on the decomposition of Ca-rich oil shale. J Therm Anal Calorim. 2018;131(3):2087-91. https://doi.org/10.1007/s1097 3-017-6823-1.

Málek J. A computer program for kinetic analysis of non-isothermal thermoanalytical data. Thermochim Acta. 1989;138(2):337-46. https://doi.org/10.1016/0040-6031(89)87270-3.

Moine EC, Groune K, El Hamidi A, Khachani M, Halim M, Arsalane S. Multistep process kinetics of the non-isothermal pyrolysis of Moroccan Rif oil shale. Energy. 2016;115:931-41. https://doi. org/10.1016/j.energy.2016.09.033.

Moine EC, Bouamoud R, El Hamidi A, Khachani M, Halim M, Arsalane S. Mineralogical characterization and non-isothermal pyrolysis kinetics of Moroccan Rif oil shale. J Therm Anal Calorim. 2018;131(2):993-1004. https://doi.org/10.1007/s1097 3-017-6632-6.

Muhammad AF, El Salmawy MS, Abdelaala AM, Sameah S. El nakheil oil shale: Material characterization and effect of acid leaching. Oil Shale. 2011;28: 528-47. https://doi.org/10.3176/oil.2011.4.06.

Ngo C, Natowitz J. Our energy future: resources, alternatives and the environment. Hoboken: Wiley; 2016.

Palayangoda SS, Nguyen QP. An ATR-FTIR procedure for quantitative analysis of mineral constituents and kerogen in oil shale. Oil Shale. 2012;29(4):344-56. https://doi.org/10.3176/oil.2012.4.05.

Qing W, Hongpeng L, Baizhong S, Shaohua L. Study on pyrolysis characteristics of Huadian oil shale with isoconversional method. Oil Shale. 2009;26(2):148-62. https://doi.org/10.3176/oil.2009.2.07.

Ren L, Xia D, Xu Y, Guo M, Sun H, Liu X. Research on pyrolysis mechanism of Huadian oil shale. Energy Procedia. 2015;66:13-6. https://doi.org/10.1016/j.egypro.2015.02.007.

Roberts E, Jelsma HA, Hegna T. In: de Wit MJ, Guillocheau F, de Wit MCJ, editors. Geology and resource of the Congo basin. Heidelberg: Springer; 2015. p. 163-91. https://doi.org/10.1007/978-3642-29482-2_9.

Saif T, Lin Q, Butcher AR, Bijeljic B, Blunt MJ. Multi-scale multidimensional microstructure imaging of oil shale pyrolysis using $\mathrm{X}$-ray micro-tomography, automated ultra-high resolution SEM,
MAPS mineralogy and FIB-SEM. Appl Energy. 2017;202:62847. https://doi.org/10.1016/j.apenergy.2017.05.039.

Sánchez-Rodríguez D, Eloussifi H, Farjas J, Roura P, Dammak M. Thermal gradients in thermal analysis experiments: criterions to prevent inaccuracies when determining sample temperature and kinetic parameters. Thermochim Acta. 2014;589:37-46. https:// doi.org/10.1016/j.tca.2014.05.001.

Shannon RD. Activated complex theory applied to the thermal decomposition of solids. Trans Faraday Soc. 1964;60:1902-13. https:// doi.org/10.1039/tf9646001902.

Solomon PR, Miknis FP. Use of Fourier transform infrared spectroscopy for determining oil shale properties. Fuel. 1980;59(12):8936. https://doi.org/10.1016/0016-2361(80)90040-X.

Strizhakova YA, Usova TV. Current trends in the pyrolysis of oil shale: a review. Solid Fuel Chem. 2008;42(4):197-201. https:// doi.org/10.3103/S0361521908040022.

Tissot BP, Welte DH. Petroleum formation and occurrence. 2nd ed. Springer, New York; 1984.

Tiwari P, Deo M. Compositional and kinetic analysis of oil shale pyrolysis using TGA-MS. Fuel. 2012a;94:333-41. https://doi. org/10.1016/j.fuel.2011.09.018.

Tiwari P, Deo M. Detailed kinetic analysis of oil shale pyrolysis TGA data. AIChE J. 2012b;58(2):505-15. https://doi.org/10.1002/ aic. 12589 .

Torrente MC, Galán MA. Kinetics of the thermal decomposition of oil shale from Puertollano (Spain). Fuel. 2001;80(3):327-34. https:// doi.org/10.1016/S0016-2361(00)00101-0.

Vyazovkin S, Burnham AK, Criado JM, Pérez-Maqueda LA, Popescu C, Sbirrazzuoli N. ICTAC Kinetics Committee recommendations for performing kinetic computations on thermal analysis data. Thermochim Acta. 2011;520(1-2):1-19. https://doi.org/10.1016/j. tca.2011.03.034.

Vyazovkin S, Chrissafis K, Di Lorenzo ML, Koga N, Pijolat M, Roduit B, et al. ICTAC Kinetics Committee recommendations for collecting experimental thermal analysis data for kinetic computations. Thermochim Acta. 2014;590:1-23. https://doi.org/10.1016/j. tca.2014.05.036.

Wang Z, Deng S, Gu Q, Zhang Y, Cui X, Wang H. Pyrolysis kinetic study of Huadian oil shale, spent oil shale and their mixtures by thermogravimetric analysis. Fuel Process Technol. 2013;110:1038. https://doi.org/10.1016/j.fuproc.2012.12.001.

Wang W, Li S, Li L, Ma Y, Yue C, He J. Pyrolysis characteristics of a North Korean oil shale. Pet Sci. 2014;11(3):432-8. https://doi. org/10.1007/s12182-014-0358-x.

Wang W, Li S, Yue C, Ma Y. Multistep pyrolysis kinetics of North Korean oil shale. J Therm Anal Calorim. 2015;119(1):643-9. https://doi.org/10.1007/s10973-014-4191-7.

Wei Z, Michael Moldowan J, Dahl J, Goldstein TP, Jarvie DM. The catalytic effects of minerals on the formation of diamondoids from kerogen macromolecules. Org Geochem. 2006;37(11):1421-36. https://doi.org/10.1016/j.orggeochem.2006.07.006.

Williams PT, Ahmad N. Investigation of oil-shale pyrolysis processing conditions using thermogravimetric analysis. Appl Energy. 2000;66(2):113-33. https://doi.org/10.1016/S0306 -2619(99)00038-0.

Yan J, Jiang X, Han X, Liu J. A TG-FTIR investigation to the catalytic effect of mineral matrix in oil shale on the pyrolysis and combustion of kerogen. Fuel. 2013;104(2):307-17. https://doi. org/10.1016/j.fuel.2012.10.024.

Yen TF, Chilingarian GV. Oil shale. Amsterdam: Elsevier Scientific Publishing Company; 1976. 